Relations industrielles

Industrial Relations

\title{
Women and the Making of the Working Class: Lyon, 1830-1870, par Laura S. Strumingher, Montréal, Eden Press, 1979, 161 pp.
}

\section{Dimitri Weiss}

Volume 34, numéro 4, 1979

URI : https://id.erudit.org/iderudit/029026ar

DOI : https://doi.org/10.7202/029026ar

Aller au sommaire du numéro

Éditeur(s)

Département des relations industrielles de l'Université Laval

ISSN

0034-379X (imprimé)

1703-8138 (numérique)

Découvrir la revue

Citer ce compte rendu

Weiss, D. (1979). Compte rendu de [Women and the Making of the Working Class: Lyon, 1830-1870, par Laura S. Strumingher, Montréal, Eden Press, 1979, 161 pp.] Relations industrielles / Industrial Relations, 34(4), 832-832.

https://doi.org/10.7202/029026ar

Tous droits réservés @ C Département des relations industrielles de l'Universite Laval, 1979
Ce document est protégé par la loi sur le droit d'auteur. L'utilisation des services d'Érudit (y compris la reproduction) est assujettie à sa politique d'utilisation que vous pouvez consulter en ligne.

https://apropos.erudit.org/fr/usagers/politique-dutilisation/ 
naître davantage sur le problème de l'alcoolisme ou de l'abus des drogues, particulièrement dans les milieux de travail, serait bien avisée d'en examiner l'approche. Plus de 400 références viennent compléter l'ouvrage pour ceux qui désirent approfondir. Soulignons enfin que le volume de 268 pages ne se vend que $\$ 8.95$ ce qui représente un exemple que plusieurs souhaiteraient voir suivi par d'autres pour des travaux de cette qualité. Souvent la qualité du papier et le prix du volume sont en relation inverse avec la qualité du contenu. Ici, nous assistons au phénomène contraire.

\section{René BOULARD}

Université Laval

Women and the Making of the Working Class: Lyon, 1830-1870, par Laura S. Strumingher, Montréal, Eden Press, 1979, $161 \mathrm{pp}$.

Laura Strumingher, depuis juillet 1979 Director of Women's Studies, University of Cincinnati, après avoir été Associate Professor of History à la State University of New York, nous présente ici la thèse de doctorat en histoire qu'elle a soutenue à l'Université de Rochester sur les ouvrières de la soie (canutes) à Lyon.

Se basant sur une recherche minutieuse et une riche documentation, fruit de ses différents séjours en France, elle décrit très bien le contexte de l'époque: la ville de Lyon, l'industrie de la soie et son organisation, la conjoncture économique, l'environnement politique, la situation sociale des femmes de condition modeste, l'horizon bouché qui les enserre dans un carcan.

J'allais dire qu'elle raconte à souhait la naissance des filatures (qui emploient des fileuses), les conditions de travail des ouvrières (et la «technologie» en cours à l'époque), y compris la durée du travail, l'exploitation multipliée des plus jeunes d'entre elles, les formes d'organisation collective...
Dès les premières lignes de sa préface, l'auteur nous fait part de sa conviction fondamentale: la division entre les travailleurs hommes et femmes a ralenti le développement de la classe ouvrière, la conscience prolétaire en formation se trouvant investie par le débat autour de l'accession des femmes au domaine (réservé) des hommes. Ceux-ci et celles-là, dit Laura Strumingher, quoiqu'en partageant certaines expériences communes de la vie de travail; n'en percevaient pas les issues de la même façon: en dépit cle la similitude de leurs conditions de travail, les hommes refusaient aux femmes l'accès à leurs associations, leur déniaient le droit à un salaire égal à travail égal, et même celui au travail tout court.

La division, voire la fissure, entre les uns et les autres était de beaucoup plus importante que les différences entre les ouvriers qualifiés et non-qualifiés, ou entre ceux des cités et ceux des campagnes.

Laura Strumingher étaye sa théorie par une documentation des plus solicles. Mais, loin d'en faire un travail universitaire aride, elle réussit à rendre l'histoire vivante, et sa thèse convaincante.

Les historiens du travail, bien sar, mais également ceux qui travaillent sur les problèmes d'organisation et de conditions de travail, désormais au coeur même des relations industrielles, ne devraient pas manquer d'en faire leur profit, de même que les chercheurs et les lecteurs qui s'intéressent à la condition historique de la femme, au travail et hors travail, à l'intention desquels il faut préciser que le présent livre paraît dans la série Monographs in Women's Studies.

Ajoutons que l'auteur collabore habituellement au Journal of Social History, Journal of Family History, Societas, Mouvement social, et Cahiers d'Histoire.

\section{Dimitri WEISS}

Université de Paris I 